\title{
EDUCAÇÃO INFANTIL E SUAS PRÁTICAS EDUCATIVAS: A IMPORTÂNCIA DA ALIMENTAÇÃO SAUDÁVEL E CONSCIENTE
}

\author{
Cleide Aparecida Pereira Cirino ${ }^{1}$ \\ Célia de Siena Rodrigues de Siqueira ${ }^{2}$ \\ Eloider Camargo ${ }^{3}$ \\ Joice Ferreira de Oliveira Alencar Cardoso ${ }^{4}$ \\ Layra Milena da Silva Suquere ${ }^{5}$ \\ Rozangela Sueli de Souza Ramos ${ }^{6}$
}

\begin{abstract}
RESUMO: Desenvolver práticas de ensino partindo do contexto de preservação da vida e bem-estar das crianças pequenas e bem pequenas envolve um conjunto de fatores como econômico, social e cultural. Uma delas é a alimentação, no qual a sua falta compromete o desenvolvimento físico, afetivo e psicomotor da criança, ter uma alimentação adequada promove uma estratégia transformadora e essencial para o ensino aprendizagem rompendo barreira que inibe sua capacidade de aprender. Portanto envolver questões ambientais, o cuidar, preservar e acima de tudo proporcionar uma alimentação saudável e consciente é fundamental para diminuir as dificuldades na aprendizagem e concentração que dificulta o rendimento escolar.
\end{abstract}

Palavras-chave: Cuidar. Conscientizar. Alimentação saudável.

ABSTRACT: Developing teaching practices starting from the context of preserving the life and well-being of young and very young children involves a set of factors such as economic, social and cultural. One of them is nutrition, in which its lack compromises the child's physical, affective and psychomotor development, having adequate nutrition promotes a transformative and essential strategy for teaching and learning, breaking barriers that inhibit their ability to learn. Therefore, involving environmental issues, caring, preserving and above all providing a healthy and conscientious diet is essential to reduce the difficulties in learning and concentration that hinder school performance.

Keywords: Caring. Aware. Healthy eating.

\footnotetext{
I Especialista em psicopedagogia clínica e Institucional pelo Instituto Superior de Educação IBITURUNA Graduada em Pedagogia pela Universidade do Estado de Mato Grosso - UNEMAT. Email: cleidecidinha@hotmail.com.

${ }^{2}$ Especialista em Educação Infantil e Especial Faculdades Integradas Mato-Grossenses de Ciências Sociais e Humanas - Mantidas pelo Instituto Cuiabano de Educação - ICE. Graduada em Pedagogia pela Faculdade Afirmativo.

3 Pós-graduada em Psicopedagogia Clínica e Institucional pelo Instituto Superior de Educação IBITURUNA. E-mail: elocamarguinho@hotmail.com

4 Especialista em Alfabetização e Letramento pelo Centro Universitário Leonardo da Vinci UNIASSELVI. Graduada em Pedagogia pela Universidade de Cuiabá - UNIC.

5 Especialista em Educação Especial e Inclusão com Ênfase em AEE pelas Faculdades Integradas de Várzea Grande - FIAVEC. Graduada em Pedagogia pela Faculdade Integradas Mato-Grossenses de Ciências Sociais e Humanas - mantidas pelo Instituto Cuiabano de Educação - ICE. E-mail: layra.milena@gmail.com

6 Pós-graduada em Educação Especial e Inclusiva com Ênfase em Deficiência Intelectual e Múltipla. Graduada em Pedagogia pela Universidade do Estado de Mato Grosso - UNEMAT. E-mail: rozangela2005@gmail.com
} 


\section{INTRODUÇÃO}

A educação alimentar abrange o campo do conhecimento transdisciplinar, Inter setorial e multiprofissional, favorecendo hábitos alimentares saudáveis garantindo o direito a uma alimentação saudável e de qualidade. Ao trabalhar atividades que envolvam alimentação, faz se necessário criar estratégias voltadas para a saúde e o meio ambiente, que visem o conhecimento e aprendizagem potencializando o processo de conscientização. Elaborar métodos que envolvam o conceito e ações de uma alimentação saudável e um ambiente favorável. Todavia, os projetos de intervenção e prevenção contribuem para o desenvolvimento da criança, o meio ambiente tem um papel importante para a prática alimentar e promoção da saúde, despertando a conscientização de preservação e cidadania, e assim, facilita a criança na descoberta de como surgem alguns alimentos, como crescem e depois são colhidos para poder chegar a nossa mesa e ser preparados para nossa alimentação.

Destacamos ainda, que as crianças são bastante curiosas e observadoras, permitindo entender desde cedo o cuidar, preservar desde que sejam mediadas, por meio de ações, demonstrações e práticas direcionada ao conhecimento, buscando da melhor maneira condições ambientais e o equilíbrio com a natureza. A educação ambiental faz parte da Política Nacional da Educação ambiental em todos os níveis escolares, principalmente se partir da infância é tão importante e eficaz, pois é nesse momento que permitem a interação social, conceito de valores e conscientização, há criança precisa compreender que ela faz parte da natureza e que o cuidar e preservar faz parte da vida. Ao ensinar uma criança os hábitos de maneira alegre e divertida, elas são capazes de transformar o aprendizado repleto de entusiasmos e satisfação, começando com crianças bem pequenas ensinar a importância de preservar a natureza e fazer demonstração de alguns alimentos que são produzidos por meio do plantio e colheita, e que esses alimentos são consumidos e fazem bem para nossa saúde.

Desenvolver atividades que tenha relação com o meio ambiente permite conciliar a teoria com a prática, lembrando diariamente sua relação com o meio ambiente e a importância das rotinas diárias criando hábitos de preservação e de alimentação saudável, e fazer uso desses recursos, envolvendo todo o ciclo, começando 
pelo plantio, mostrando os formatos das sementes, a terra, água e toda essa preparação e preocupação neste processo de cultivar, colher e ser preparado para alimentação.

Essa experiência ajuda no desenvolvimento psicomotor da criança e contribui para que apropriem de hábitos para uma alimentação saudável. Por isso é importante auxiliar nessa prática educativa, estimulando desde cedo as crianças pequenas ensinando desde sempre a importância de consumir alimentos naturais e variados, envolvendo-se nessa descoberta de como plantar, de como cuidar, e quando colher. E assim, é nessa etapa que despertamos sua curiosidade e a percepção visual, mostrando desde o momento da semeadura e todas as etapas até chegar ao seu crescimento. Nesse sentido trabalhar espaços, tempos, quantidades, relações e transformações conforme a BNCC (Base Nacional Comum Curricular) na educação infantil, tem tudo a ver com o meio ambiente e seus recursos, a importância de trabalhar os espaços e tempos diversos, as transformações das plantas, o cultivar até a hora da colhida das hortaliças, frutas e verduras.

A alimentação faz parte do desenvolvimento infantil fundamentando em uma alimentação saudável e nutritiva. A educação alimentar busca essa aproximação com a natureza e a preocupação com os recursos naturais, fazendo com que a criança perceba que o cuidar e o aprender fazem parte do cotidiano diário. Criando estratégias de incentivar as descobertas individualmente e coletivamente, além de ser educativo torna-se empolgante, dinâmico e estimulante. Ensinar a criança atividades que preserve o meio ambiente São importantes para o desenvolvimento dos pequenos, a primeira vivencias é essencial para a vida adulta, criar hábitos que desenvolva as habilidades físicas, cognitivas, social e afetivas São experiências únicas em todas as dimensões social, cultural e individual, incentivar a criança a se perceber como ser integrante transformador e consciente. Despertar o interesse e a curiosidade da criança torne-se uma boa solução para a aprendizagem, reconhecer que a construção do conhecimento é um empreendimento que envolve o ambiente e as interações e que ela precisa de experimentações e experiência ajudando a construir sua identidade e autonomia, em diferentes esferas fazendo uso da imaginação interesse de descobrir o seu corpo e os espaços que os cercam. O desenvolvimento integral saudável da criança 
começa com sua observação e interação com o mundo, adaptando aos ambientes construindo os sentidos de que a aprendizagem englobam seus aspectos intelectual, afetivo, social e físico, o conviver com a natureza e sociedade, propicia oportunidade de conhecer, aprender, observar, questionar principalmente o cuidar seja de um objeto ou uma planta estimulando a criatividade, curiosidade, participação, exploração, fantasia, iniciativa, manifestação de opiniões próprias e discussão de ideias, possibilitando assim a interação social reconhecendo toda sua potencialidade .

\section{DESENVOLVIMENTO}

\section{I Importância do bem-estar faz parte do desenvolvimento da criança}

A primeira infância contribui no desenvolvimento e aprendizagem da criança, é neste período que começa a se desenvolver e aprender hábitos, por meio de mediação, sentidos, o motor e o psíquico. Vygotskt (1998), ressalta que a criança possui uma riqueza de informações e estudo de suas capacidades, que não tem ligação direta com o conhecimento que ela possui, mas que desempenham papel importante no seu desenvolvimento.

Para o autor esta capacidade que a criança tem de informações, facilita na complexidade dos estímulos, ela desenvolve através de experiências vivenciada, por meio de gestos e movimentos, no ato de brincar, correr e pular, ofertando a criança a satisfação de suas necessidades básicas, propiciando a aprendizagem por estímulos e motivação. Compreender essas relações é de demasiada importância no qual a criança neste momento passa a reproduzir traços da sociedade e adquirir uma relação social, permitindo questionamentos $\mathrm{e}$ indagações, começam imitar os adultos, as ações praticadas contribui para o seu desenvolvimento. Com isso é importante dizer que todas essas ações podem ser observadas e possuem particularidades únicas, nas quais estabelece uma relação comum em determinados objetos, tempos e espaços, suas ações são reguladas pelos resultados dos estímulos obtidos, buscar compreender que o bemestar e a disposição de uma criança dependem de uma boa alimentação é parte crucial para o seu desenvolvimento contribuindo assim para com o ensino aprendizagem.

A educação infantil é dividida em berçário, maternal, jardim e pré-escola, atendendo criança de zero até seis anos. Essa organização é compreendida como 
CMEI, CRECHES e CEIC, cada uma delas corresponde a cada faixa etária da criança/ estudante. Antigamente as unidades educacionais tinha caráter apenas assistencial apenas o cuidar, hoje as leis asseguram todos os direitos, não penas o cuidar, mas de desenvolver e a socializar.

A constituição de 1988 criou leis que garante o direito à educação para educação infantil, esses direitos são educar, cuidar, brincar, alimentação e higienização de maneira integrada para que os resultados sejam satisfatórios de acordo com as leis de direitos e deveres. Em conformidade com as Diretrizes Curriculares Nacionais para a educação infantil. Os direitos e as condições das crianças são assegurados, bem como incluir uma alimentação saudável.

Art. 205. A educação, direito de todos e dever do Estado e da família, será promovida e incentivada com a colaboração da sociedade, visando ao pleno desenvolvimento da pessoa, seu preparo para o exercício da cidadania e sua qualificação para o trabalho. Art. 206. O ensino será ministrado com base nos seguintes princípios: I - igualdade de condições para o acesso e permanência na escola (BRASIL, I998).

De acordo com Constituição Federal garantir o bem-estar das crianças/alunos é um dever do Estado e da família promover o bem-estar e incentivar a sociedade a fazer valer esses direitos que lhes são computados, e assim o incentivo e fortalecimento dos Programas Nacional de Alimentação Escolar (PNAE) oferece alimentação escolar e ações de educação alimentar e nutricional há todas as crianças/ alunos em todas as etapas. Esse incentivo do Governo Federal repassa, ao Estado, Municípios e Escolas Federais, valores financeiros para alimentação de todos os estudantes, de acordo com o número de matriculados em cada rede de ensino.

Por isso a fiscalização da sociedade é importante garantir adequadamente essa distribuição que é feita pelo programa do PNAE, dos Conselhos de Alimentação Escolar (CAE), e pelo FNDE, pelo Tribunal de Contas da União (TCU), pela Controladoria Geral da União (CGU) e pelo Ministério Público. Em 12 de julho de 1994, a descentralização foi instituída por meio da Lei no 8.913/1994. A consolidação da citada descentralização deu-se com a Medida Provisória no I.784, de I4 de dezembro de 1998, que instituiu a transferência automática dos recursos do programa com mais 
agilidade nesse processo de execução do PNAE (BRASIL, 2008).

Ao longo dos anos o sistema de distribuição alimentar foi-se aperfeiçoando, e no ano de 2000 criaram o Conselho Nacional de Segurança Alimentar e Nutricional (CONSEA) que promoveu a valorização da Política de Segurança Alimentar e Nutricional (PNSAN) garantido o direito à alimentação adequada, diante de tais necessidade e criaram a Lei Orgânica de Segurança Alimentar e Nutricional (LOSAN) que dispõe sobre o Sistema Nacional de Segurança Alimentar e Nutricional (SISAN) com a implantação do direito humano a alimentação adequada e saudável perante a constituição (CONSEA, 20I0).

Para garantir uma alimentação saudável foram necessários elaborar documentos que implementasse as políticas públicas de saúde e ações governamentais, especialmente as desenvolvidas pelos Ministérios do Desenvolvimento Social e de Combate à Fome, da Saúde e da Educação (SANTOS, 2012. P 453).

A Educação Infantil obteve avanços e conquistas da qual a criança passou a ser reconhecida como sujeito social e histórico que faz parte de uma sociedade, que tem voz, que são protagonistas de suas vidas, tendo potencial e sendo sujeito de direitos, conforme o RCNEI (1998, v. oI, p. 2I), Ampliaram a representações das ações de alimentação e nutrição, no sentido de uma educação emancipatória, regida pelas concepções da promoção da saúde.

Diante disso, o reconhecimento da educação nutricional voltada para as crianças/ estudantes é um fator fundamental para o seu desenvolvimento, é assim torna essencial que o governo e órgãos responsável busque recursos que firme uma alimentação saudável e de boa qualidade.

\section{CONSCIENTIZAR AS PRÁTICA EDUCACIONAL QUE GARANTE O DESENVOLVIMENTO INFANTIL.}

Entendemos, assim, que a prática educacional evolve todas as etapas da educação, desde a infância até chegar à adolescência e depois a fase adulta, pois cada etapa envolve diversas mudanças e hábitos. Compreender e reconhecer que a falta de alimentação pode desencadear problemas de saúde e atraso no desenvolvimento das crianças/estudantes e sempre com olhar voltado as peculiaridades $e$ as reais 
necessidades da criança de o a 6 anos de idade, sendo imprescindível desenvolver uma alimentação nutritiva e saudável focadas no seu bem-estar. Contudo, ter uma alimentação saudável ajuda no desenvolvimento da criança/estudante, essa prática tem que ser pensada desde muito cedo, e a importância de uma alimentação balanceada e nutritiva. Pensar em ter uma boa alimentação é essencial para prevenir qualquer tipo de distúrbio alimentar no futuro, sem falar que ajuda a prevenir de algumas doenças, como obesidade, desnutrição dificultando a capacidade de concentração comprometendo o seu rendimento e retardando a vida escolar da criança/estudante.

Deste modo, entendemos que existem uma valorização do Direito Humano à Alimentação Adequada e garantia da Segurança Alimentar e Nutricional, a Educação Alimentar e Nutricional é um campo de conhecimento e de prática contínua e permanente, que visa promover a prática autônoma e voluntária de hábitos alimentares saudáveis, que promovam saúde e que respeitem a diversidade cultural e que sejam ambientais, culturais, econômicas e socialmente sustentáveis (Brasil, 2012). Estabelecer metas que desenvolva o cuidar e educar na educação infantil, proporcionando o conforto adequado, baseando na concepção do respeito as diversidade de cada um, criar ações de tempo e espaço que estimulem a curiosidade e liberdade respeitando as suas especificidades individual com objetivo de manter toda atenção nesta fase que se brinca, pula, e para isso faz se necessário ter uma boa alimentação para a realização de todos esses movimentos e assim adquirir hábitos alimentares garantindo recebimentos de todos os nutrientes necessário. Portanto, importante destacar que é na educação infantil que começa a etapa de transição nutricional, aos poucos as crianças vão recebendo os alimentos e descobrindo o sabor dos alimentos e o paladar e assim adquirindo o gosto por pela alimentação. Segundo Mello (2014, p. 94), há alimentação das crianças pequenas e bem pequenas é um processo lento que exigem persistência, sendo construído no dia a dia na instituição. Portanto, a alimentação faz parte do aprendizado da criança onde cada prato representa uma situação diversas, essa prática é realizada por meio de observação diários, fazendo com que a criança ao se alimentar ela possa demostrar com gestos e 
movimentos o momento de ao querer mais e assim ter noção de autonomia com relações as suas preferencias alimentar servida nas rotinas diárias.

E assim, a criança vai construindo sua autonomia constantemente, por meio de estímulos, direcionando a alimentação como um momento de diversão fazendo uso de brincadeiras, gestos e movimentos, onde cada uma é planejada, conduzida e monitorada, considerando que é na educação infantil que a criança que começa a ter as suas necessidades básicas tanto nos aspectos individual e social.

\subsection{Alimentação saudável teoria e prática}

Há qualidade de uma alimentação distribuída às escolas são essenciais para as crianças/estudantes, principalmente em escolas públicas, devido à vulnerabilidade social, esta preocupação encontra em todas as esferas da educação, partindo do cuidar, educar e o bem-estar da criança, para garantir esse bem-estar é de fundamental importância proporcionar todas as refeições, principalmente o café da manhã e assim seguindo as outras refeições diárias. Promover uma alimentação nutritiva e saudável é buscar compreender a valorização dos estudantes, criando hábitos saudáveis que favoreçam no crescimento, desenvolvimento, bem-estar e ajudem à prevenção de doenças evitáveis na sua idade (Pardal, 1990).

Para tanto, é essencial as refeições nas escolas suprir as necessidades básicas fazem parte do direito as crianças e adolescente, tem direito de proteção à saúde, e ao lazer, mediante a efetivação de políticas públicas que garantem desde nascimento ate a vida adulta garantindo o seu bem estar. $O$ processo de desenvolvimento infantil está relacionado as condições econômicas, sociais e cultural, bem como o meio em que a criança está inserida, abrange um processo global dinâmico de mudanças, levando em consideração as condições de vida de cada um principalmente com relações aos alimentos e nutrientes distribuídos as crianças, pois as mudanças acontecem rápido e a necessidade de uma alimentação saudável e adequada e um ambiente favorável é um fator determinante para o indivíduo. $\mathrm{O}$ ambiente escolar dispõe de condições favoráveis que proporciona qualidade de vida das crianças/estudante seja no bem-estar físico e psíquico, ofertando um mundo de possibilidades e imaginação por meio das 
brincadeiras, fantasias, brinquedos, os espaços e tempo para o brincar, dormir e principalmente alimentar-se, a fim de que as crianças alcancem objetivos sem limitar sua curiosidade e imaginação.

Portanto, os momentos da alimentação, da higiene e do repouso, são questões fisiológicas necessária nas rotinas diárias envolvendo os gestos, os movimentos de maneira planejada, conduzida e monitorada constituindo o aprendizado para toda infância.

\section{CONCLUSÃO}

Neste artigo faz-se uma reflexão da importância de uma alimentação saudável e nutritiva que consiste no cuidar e educar garantindo o direito à vida propiciando um ambiente agradável e favorável para o desenvolvimento infantil.

O ambiente escolar de acordo com Taubenschlag (2009. p. II), diz que ao proporcionar a eficácia, depende de como as atividades são aplicadas, para que possa garantir a sua qualidade torna necessário à qualificação em fazê-lo para poder contribuir com a formação integral do aluno. Portanto, a qualificação da educação Infantil é promover e aprimorar recursos para o desenvolvimento da criança pequena e bem pequena, deixando de ser apenas o cuidar, e sim remete a todas as esferas entrelaçados entre cuidar, educar, proteger, alimentar entre outros. Segundo Redin (1998.p 7I), faz-se escola para desencadear novas formas de satisfação. Ao mesmo tempo em que se veiculam conteúdos formais é preciso se questionar: que satisfação pode ter em fazer isto? Além do direito que a criança tem em ser feliz, a cultura, o saber, de maneira organizada, inteligente e sensibilizada.

Por tanto, esse questionamento em ser e fazer torna necessário para facilitar o desenvolver da criança na formação de hábitos, buscando diálogos a cerca da valorização cultural, social e afetivo, e que este seja devidamente planejado, internacionalizado, contextualizado e significativo. A educação alimentar e sustentável faz parte da educação escolar em diversos seguimentos do conhecimento de diversos autores. E esta inserido transversalmente no currículo escolar, fortalecendo a promoção da saúde humana e ambiental, possibilitando que a criança seja incentivada a ter uma alimentação saudável e satisfatória para seu bem estar. Dessa 
forma, percebe-se que a alimentação é um dos fatores importante no combate à fome, a desnutrição e na proteção da saúde das crianças/estudante, e fortalecer vínculos de confiança fazendo com que sinta segura e acolhida, facilitando melhor compreensão aos hábitos de sustentabilidade e alimentação saudável.

\section{REFERÊNCIAS}

BRASIL. Resolução/FNDE/CD/ no. 38 de I6 de Novembro de 2021. Dispõe sobre o atendimento da alimentação escolar aos alunos da educação básica no Programa Nacional de Alimentação Escolar - PNAE. Brasília (DF): Diário Oficial da União, 2021.

BRASIL: http://portal.mec.gov.br/seesp/arquivos/pdf/constituicao.pdf: Presidência da República. Casa Civil. Constituição da República Federativa do Brasil de 1988. Brasília, DF: Presidência da República, 1988. Disponível em: < http://pactoensinomedio.mec.gov.br/images/pdf/constituicao_educacao.pdf >. Acesso em: 13 de Dezembro 2021;

BRASIL: RESOLUÇÃO № 21, DE I6 DE NOVEMBRO DE 2021. Altera a Resolução CD/FNDE no 6, de 8 de maio de 2020, que dispõe sobre o atendimento da alimentação escolar aos alunos da educação básica no âmbito do Programa Nacional de Alimentação Escolar - PNAE/ https://www.nescon.medicina.ufmg.br/ biblioteca/imagem/ alessandra-pereira-jesus.pdf, Acesso em 22 de Dezembro de 2021;

CENPEC. Centro de pesquisa em educação, cultura e ação comunitária. https://www.cenpec.org.br/tematicas?category $=$ infancias \&campaign $=2023683979 \&$ co ntent $=\{$ ads $\} \&$ keyword $=$ educa $\% \mathrm{C}_{3} \% \mathrm{~A}_{7 \%} \mathrm{C}_{3} \% \mathrm{~A}_{30} \% 20$ infantil\&gclid $=\mathrm{CjoKCQiA} 5 \mathrm{Ou}$ NBhCRARIsACgaiqVdDR5IyhNiy6jBNobh3xQrokiLIB9dR7AmZcvRonsG4DxI29q clZgaAikhEALw_wcB, Acesso em 23 de Dezembro de 2021;

FNDE: Fundo Nacional de Desenvolvimento da Educação, Ministério da Educação. Manual de orientação para alimentação escolar na educação infantil, ensino fundamental, ensino médio e na educação de jovens e adultos/ organizado por Francisco de Assis Guedes de Vasconcelos... etal. instruções operacionais para nutricionistas vinculados ao PNAE e diretores escolares, 2. edição. Brasília, DF, 20012.

FNDE: Fundo Nacional de Desenvolvimento da Educação; http://www.fnde.gov.br/acessibilidade/item/3535-portaria-interministerialn\%C2\%BA- acesso em 22 de Dezembro de 2021;

MELLO, M.M.S. Nutrição e Habitos Alimentares Saudaveis na Primeira Infancia. In: Rapoport, A. et all. O dia na educação infantil. Ed. Mediação. Porto Alegre, 2014, pg 94. 
METODOLOGIAS DA ALIMENTAÇÃO, HIGIENE E REPOUSO Educar e Cuidar na Educação Infantil: Caminhos Metodológicos Para a Rede Municipal de Joinville file://C:/Users/Semp/Downloads/Metodologia-daalimenta\% $\mathrm{C}_{3} \% \mathrm{~A}_{7} \% \mathrm{C}_{3} \% \mathrm{~A}_{30}$-da-higiene-e-do-repouso-na-Educa\% $\mathrm{C}_{3} \% \mathrm{~A}_{7} \% \mathrm{C}_{3} \% \mathrm{~A}_{3}$ Ensino-de-Joinville.pdf. Acesso em 22 de Dezembro de 2021

PARDAL, M. Educação para a saúde - conceitos e perspectivas. Saúde e Escola, 6, III4. 1990;

REDIN, Euclides. O espaço e o tempo da criança: se der tempo a gente brinca. Ed. Mediação. Porto Alegre, 1998, p 7 I.

SANTOS, L.A.S. O fazer educação alimentar e nutricional: algumas contribuições para reflexão. Ciência \& Saúde Coletiva, v. 17, n. 2, p. 453-462, 2012.

TAUBENSCHLAG, Carlos Alfredo. Atividades Lúdicas: para vier em harmonia. Ed. Paulinas, SP. 2009, p ir.

UFPE; Universidade Federal de Recife; https://repositorio.ufpe.br/ bitstream/ 123456789/23871/I/SANTOS\%2C\%20Deborah\%20Maria\%2odos.pdf. Acesso em i3 de Dezembro de 2021;

VIGOTSKI, Lev Semenovich. A Formação Social da Mente: O desenvolvimento dos Processos Psicologicos Superiores. Trad. Jose Cipolla Neto, Luis Silveira Menna Barreto, Solange Castro Afeche. 6 Ed. SP: Martins Fontes,1998. 